\title{
Theofilos
}

A Nordic open access journal in Theology, Philosophy and Culture

Published by NLA University College - in partnership with Johannelund School of Theology

Available at www.theofilos.no

\section{Science and Faith: Friendly Allies, Not Hostile Enemies ${ }^{1}$}

\author{
John Lennox \\ Professor of Mathematics (Emeritus), Associate Fellow of the Saïd Business School, and Emeritus \\ Fellow and Pastoral Adviser of Green Templeton College, \\ The University of Oxford \\ www.jobnlennox.org
}

Contemporary science is a wonderfully collaborative activity. It knows no barriers of geography, race, or creed. At its best, it enables us to wrestle with the problems that beset humanity, and we rightly celebrate when an advance is made that brings relief to millions.

I have spent my life as a pure mathematician, and I often reflect on what physics Nobel Prize-winner Eugene Wigner called "the unreasonable effectiveness of mathematics." How is it that equations created in the head of a mathematician can relate to the universe outside that head? This question prompted Albert Einstein to say, "The only incomprehensible thing about the universe is that it is comprehensible." The very fact that we believe that science can be done is a thing to be wondered at.

Why should we believe that the universe is intelligible? After all, if, as certain secular thinkers tell us, the human mind is nothing but the brain and the brain is nothing but a product of mindless unguided forces, it is hard to see that any kind of truth, let alone scientific truth, could be one of its products. As chemist J.B.S. Haldane pointed out long ago: if the thoughts in my mind are just the motions of atoms in my brain, why should I believe anything it tells me - including the fact that it is made of atoms? Yet many scientists have adopted that naturalistic view, seemingly unaware that it undermines the very rationality upon which their scientific research depends!

It was not - and is not - always so. Science as we know it exploded on to the world stage in Europe in the sixteenth and seventeenth centuries. Why then and why there? Alfred North Whitehead's view, as summarized by C.S. Lewis, was that "men became scientific because they expected Law in Nature, and they expected Law in Nature because they believed in a Legislator."2 It is no accident that Galileo, Kepler, Newton, and ClerkMaxwell were believers in God.

Melvin Calvin, American Nobel Prize laureate in biochemistry, finds the origin of the foundational conviction of science - that nature is ordered - in the basic notion "that the universe is governed by a single God, and is not the product of the whims of many gods, each governing his own province according to his own laws. This monotheistic view seems to be the historical foundation for modern science."3

Belief in God, far from hindering science, was the motor that drove it. Isaac Newton, when he discovered the law of gravitation, did not make the common mistake of saying "now [that] I have a law of gravity, I don't need God.” Instead, he wrote Principia Mathematica, the most famous book in the history of science, expressing the hope that it would persuade 
the thinking reader to believe in a creator.

Newton could see what, sadly, many people nowadays seem unable to see: that God and science are not alternative explanations. God is the agent who designed and upholds the universe; science tells us about how the universe works and about the laws that govern its behavior. God no more conflicts with science as an explanation for the universe than Henry Ford conflicts with the laws of the internal combustion engine as an explanation for the motorcar. The existence of mechanisms and laws is not an argument for the absence of an agent who set those laws and mechanisms in place. On the contrary, their very sophistication, down to the fine tuning of the universe, is evidence for the Creator's genius. For Johannes Kepler, German seventeenth-century mathematician, astronomer and astrologer: "The chief aim of all investigations of the external world should be to discover the rational order which has been imposed on it by God and which he revealed to us in the language of mathematics." 4

As a scientist, then, I am not ashamed or embarrassed to be a Christian. After all, Christianity played a large part in giving me my subject.

The mention of Kepler brings me to another issue. Science is, as I said earlier, by and large a collaborative activity. Yet real breakthrough is often made by a lone individual who has the courage to question established wisdom and strike out on his or her own. Johannes Kepler was one such. He went to Prague as assistant to the astronomer Tycho Brahe, who tasked him with making mathematical sense of observations of planetary motion in terms of complex systems of circles. The view that perfect motion was circular came from Aristotle and had dominated thought for centuries. But Kepler just couldn't make circles fit the observations. He took the revolutionary step of abandoning Aristotle, approaching the observations of the planets from scratch, and seeing what the orbits actually looked like. Kepler's discovery, that the planetary orbits were not circular but elliptical, led to a fundamental paradigm shift for science.

Kepler had the instinct to pay careful attention to things that didn't fit into established theory. Einstein was another such groundbreaker. Things that don't fit in can lead to crucial advances in scientific understanding. Furthermore, there are matters that do not fit into science. For, and it needs to be said in the face of widespread popular opinion to the contrary, science is not the only way to truth. Indeed, the very success of science is due to the narrowness of the range of its questions and methodology.

Nor is science coextensive with rationality. If it were, half our university faculties would have to shut. There are bigger matters in life - questions of history and art, culture and music, meaning and truth, beauty and love, morality and spirituality, and a host of other important things that go beyond the reach of the natural sciences, and, indeed, of naturalism itself. Just as Kepler was initially held back by an assumed Aristotelianism, could it not be that an a priori naturalism is holding back progress by stopping evidence from speaking for itself?

It is to such things that my mind turns when I think of Jesus, the human, above all others, who did not fit into the preconceptions of this world. Just as Johannes Kepler revolutionized science by paying close attention, observing why the planets did not fit in to the mathematical wisdom of the time, I claim that my life and that of many others has been revolutionized by paying close attention to Jesus and 
why He did not, and still does not, fit in to the thinking of this world. Indeed, the fact that Jesus did not fit in is one of the reasons I am convinced of His claim to be the Son of God.

For instance, Jesus does not fit into the category of literary fiction. If $\mathrm{He}$ did, then what we have in the Gospels is inexplicable. It would have required exceptional genius to have invented the character of Jesus and put into His mouth parables that are in themselves literary masterpieces. It is just not credible that all four gospel writers with little formal education between them just happened simultaneously to be literary geniuses of world rank.

Furthermore, there are relatively few characters in literature who strike us as real people, whom we can know and recognize. One of them is my intellectual hero, Socrates. He has struck generation after generation of readers as a real person. Why? Because Plato did not invent him. So it is with Jesus Christ. Indeed, the more we know about the leading cultures of the time, the more we see that, if the character of Jesus had not been a historical reality, no one could have invented it. Why? Because He did not fit in to any of those cultures. The Jesus of the Gospels didn't fit anyone's concept of a hero. Greek, Roman, and Jew - all found Him the very opposite of their ideal.

The Jewish ideal was that of a strong military general, fired with messianic ideals and prepared to fight the Roman occupation. So when Jesus eventually offered no resistance to arrest, it was not surprising that His followers temporarily left Him. He was far from the Jewish ideal leader.

As for the Greeks, some favored the Epicurean avoidance of extremes of pain and pleasure that could disturb tranquility. Others preferred the rationality of
Stoicism, which suppressed emotion and met suffering and death with equanimity, as Socrates had done.

Jesus was utterly different. In the Garden of Gethsemane, facing such intense agony that $\mathrm{He}$ sweat drops of blood, $\mathrm{He}$ asked God to let Him skirt the torturous cross. No Greek would have invented such a figure as a hero.

And the Roman governor Pilate found Christ unworldly and impractical when Jesus told him: "My kingdom is not of this world ... For this purpose I was born and for this purpose I came into the world - to bear witness to the truth" (John 18:36-37).

So, Jesus ran counter to everyone's concept of an ideal hero. Indeed, Matthew Parris, an atheist, suggested in the Spectator recently that if Jesus hadn't existed not even the church could have invented Him! Jesus just did not fit in.

Nor did His message. St. Paul tells us that the preaching of the cross of Christ was regarded by the Jews as scandalous, and by the Greeks as foolish. The early Christians certainly could not have invented such a story. Where, then, did it come from? From Jesus Himself, who said, "The Son of Man came not to be served but to serve, and to give his life as a ransom for many" (Matt. 20:28). Jesus did not fit into the world. So they crucified Him and tried to fit Him in a tomb. But that did not work either. He arose from the dead on the third day.

But doesn't this go against the grain of the science I was praising earlier? Aren't such miracles impossible because they violate the laws of nature? I disagree. To use an illustration based on one offered by C.S. Lewis, on each of two nights, if I put ten pounds (British currency) into my drawer, the laws of arithmetic tell me I have twenty pounds. If, however, on 
waking up I have only five pounds in the drawer I don't conclude that the laws of arithmetic have been broken but possibly the laws of England. 5 The laws of nature describe to us the regularities on which the universe normally runs. God, who created the universe with those laws, is no more their prisoner than the thief is prisoner of the laws of arithmetic. Like my room, the universe is not a closed system, as the secularist maintains. God can, if He wills, do something special, like raise Jesus from the dead.

Note that my knowledge of the laws of arithmetic tells me that a thief has stolen the money. Similarly, if we did not know the law of nature that dead people normally remain in their tombs, we should never recognize a resurrection. We could certainly say that it is a law of nature that no one rises from the dead by natural processes. But Christians do not claim that
Jesus rose by natural processes, but by supernatural power. The laws of nature cannot rule out that possibility.

Philosopher David Hume said that you must reject a miracle as false, unless believing in its falsity would have such inexplicable implications that you would need an even bigger miracle to explain them. That is one good reason to believe in the resurrection of Jesus. The evidence of the empty tomb, the character of the witnesses, the explosion of Christianity out of Judaism, and the testimony of millions today are inexplicable without the resurrection. As Holmes said to Watson: "How often have I said to you that when you have eliminated the impossible, whatever remains, however improbable, must be the truth?" As Russian Christians say at Easter: "Khristos Voskryes. Voiistinu Voskryes! Christ is risen. He is risen indeed!"

\footnotetext{
Notes

1 Previously published in the Winter 2015 issue of the C.S. Lewis Institute publication Knowing \& Doing (www.cslewisinstitute.org/Science_and_Faith_Friendly_Allies_Not_Hostile Enemies_FullArticle). Published in Theofilos with permission from Dr. John Lennox (www.johnlennox.org).

2 C.S. Lewis, Miracles: A Preliminary Study, London: Collins), 1947), 110.

${ }^{3}$ Melvin Calvin, Chemical Evolution (Oxford: Clarendon Press, 1969), 258.

4 Johannes Kepler (1571-1630), Astronomis Nova de Moti- 4 Miracles, 62.

${ }^{5}$ Lewis, op cit, 62.
} 